\title{
ADMINISTRACIÓN POLICIAL EN DEMOCRACIA
}

\author{
LUIS Villalobos GaRCíA*
}

\section{RESUMEN}

Este trabajo tiene por objetivo proponer elementos conceptuales y procedimentales del manejo administrativo de las corporaciones de policía, entendida como la actividad de gestión de la función policial requerida para el cumplimiento de su mandato institucional, manejo que está articulado por tres dimensiones y categorías de análisis: a) política, b) derecho y c) administración. Al proponer y establecer estos componentes, se busca sistematizar y ordenar los enfoques analíticos de la administración policial. Sistematizar y ordenar, para este trabajo, implica reflexionar y proponer los componentes de la praxis administrativa de las corporaciones de policía, para sustentar desempeños en términos de legitimidad, legalidad así como de eficiencia y eficacia en el cumplimiento de sus objetivos.

\section{Palabras clave:}

Administración policial, Administración pública, Seguridad ciudadana, Función policial, Legitimidad, Legalidad, Eficiencia, Eficacia.

\section{ABSTRACT}

This article has the objective of proposing conceptual and procedural elements about the management of police institutions, understood as the administrative activity that the police function requires to fulfill its institutional mandate. Such management is articulated by three dimensions and categories of analysis: a) polity, b) law and c) administration. By proposing these components, the aim is to systematize and order the analytical approaches of Police Administration. Systematize and order, for this paper, implies reflecting and proposing the components

* Investigador-docente de la Facultad de Derecho de la Universidad Anáhuac. Doctor en Administración Pública; ganador del primer lugar del premio del Instituto Nacional de Administración Pública (2008). 
of the administrative praxis of police corporations, to support performance in terms of legitimacy, legality as well as efficiency and effectiveness in compliance of its objectives.

\section{Keywords:}

Police administration, public administration, citizen security, police function, legitimacy, legality, efficiency, effectiveness.

\section{INTRODUCCIÓN}

La aplicación del marco teórico consolidado en la Administración Pública al trabajo policial, tiene, entre otros, dos propósitos: 1/ aportar en el mejoramiento de las capacidades de gestión policial al utilizar el conocimiento consolidado en la Administración Pública, lo que permite reflexionar sistemáticamente respecto a estas funciones, buscando ampliar las probabilidades de que las corporaciones cumplan con su mandato institucional, mejorar la calidad de su funcionamiento en términos de legalidad, legitimidad y eficiencia-eficacia del desempeño policial, orientar el trabajo de la policía a la consecución de impactos posibles de ser verificables, y 2 / iniciar un proceso de integración formal de mecanismos, conceptos y prácticas de la administración policial; para esto, se identifican y establecen temáticas asociadas al desempeño de las policías y se describen las capacidades requeridas por sus directivos.

Parte de dos supuestos de referencia:

a. El manejo de las instancias público-gubernamentales es sustancialmente distinto del manejo de las organizaciones privadas, a partir de considerar las diferencias de los propósitos de ambos tipos de organizaciones: vista como un sistema, el objetivo conjunto de la administración pública es la gobernabilidad de los Estados, en tanto que el propósito de las empresas comerciales es la obtención de rentabilidad financiera.

b. Al interior del sistema público administrativo, el manejo de las corporaciones de policía es sustancialmente diferente a la gestión de cualquier instancia de gobierno, ya que las policías están facultadas para el empleo de la fuerza. ${ }^{1}$

Históricamente se ha carecido de esquemas y estrategias de administración formales para el manejo de las policías, lo que ha propiciado una falta de conceptos y términos propios para este ámbito, y por lo tanto, que se carezca de elementos que posibiliten definir una agenda de trabajo académico y esquemas de análisis/reflexión formales de mayor alcance, respecto a los procesos del desempeño

1 "Estado es aquella comunidad humana que, dentro de un determinado territorio (el territorio es elemento distintivo), reclama (con éxito) para sí el monopolio de la violencia física legítima. Lo específico de nuestro tiempo es que a todas las demás asociaciones e individuos sólo se les concede el derecho a la violencia física en la medida en que el Estado lo permite. El Estado es la única fuente del "derecho" a la violencia."Weber, Max, La politica como vocación, México, Alianza Editorial, trad. Francisco Rubio Llorente, México, 2009, pp. 83-84. 
y función policiales, elementos requeridos por las corporaciones para el cumplimiento de su mandato institucional. Esta falta de referentes teórico-académicos conlleva a que la administración de las policías, así como el desempeño policial generalizado, se realice con amplios márgenes de discrecionalidad, así como la falta de categorías analíticas que posibiliten determinar si el trabajo de las corporaciones de policía se ha realizado bien o no, lo cual compromete la consecución de los objetivos de su trabajo.

Parte de considerar a la ciencia de la Administración Pública como la serie de conocimientos, mecanismos y herramientas que utilizan las instancias públicas para cumplir con el mandato legal que define su existencia, así como de considerar que los funcionarios y directivos de la policía son los encargados de la administración de sus corporaciones y a los empleados (tanto los policías como el personal de apoyo administrativo) como el factor determinante para alcanzar los objetivos y metas. Presenta las áreas de estudio que proporcionan un marco de análisis de la dirección en funciones específicas, que como propone Terry (2002) conforman el ciclo administrativo (organización, dirección, planeación-control y evaluación), ${ }^{2}$ así como temas particularmente asociados a la actuación policial: la supervisión, la academia de policía, la atención de quejas, la comunicación interna, y particularmente, el diseño e implementación de sistemas de rendición de cuentas policial.

Retoma el análisis respecto a las diferencias entre las organizaciones privadas y públicas y sus esquemas y praxis administrativos, distinción fundamental para el estudio de las organizaciones de policía, ya que éstas no son sólo sustancialmente diferentes a los negocios privados, sino que son incluso distintas a otras áreas de la función pública por el carácter de las funciones de vigilancia, sanción y el atributo legal del empleo de la fuerza. Es así que esta propuesta es un acercamiento y aplicación de la teoría de la administración pública al análisis del desempeño policial y su manejo administrativo.

Las categorías analíticas propuesta en este trabajo, corresponden a la administración de policías de sistemas gubernamentales democráticos, ${ }^{3}$ y en este sentido, el proceso de transformación de una corporación policial convencional hacia una que opera con esquemas de toma de decisiones democráticas (reforma policial democrática), conducido por un método adecuado y a través del empleo de instrumentos técnicos, tiene por objetivos lograr que la policía: 1) atienda, antes que nada, las necesidades de seguridad del ciudadano; 2) entienda y ejerza el desempeño policial como un mecanismo de protección de los derechos humanos; 3) se oriente por una política de transparencia y rendición de cuentas; 4) posibilite el escrutinio y evaluación externa de su desempeño por parte de actores civiles; 5) realice un trabajo policial con estricto apego a la ley, y 6) función policial orientada

2 George Terry, uno de los principales teóricos modernos de la administración, propone esta división del proceso administrativo: organización, planeación, dirección/control y evaluación, conceptos que son retomados en la definición del modelo de organización de la administración policial que se detallará adelante.

3 Para formas de gobierno no democráticas, los criterios de actuación policial son diferentes, principalmente por los parámetros de legitimidad del desempeño. 
a la consecución de impactos capaces de ser verificados empíricamente, en términos de eficacia y eficiencia del desempeño policial. ${ }^{4}$

\section{ADMINISTRACIÓN PÚBLICA, PRIVADA Y POLICIAL}

Frecuentemente las organizaciones públicas y sus encargados son criticados —no sin falta de razón - por la ineficiencia de su desempeño al comparárseles con los éxitos que obtienen las organizaciones privadas. Estas críticas pueden ser válidas en algunas circunstancias, pero debe considerarse que el trabajo de las organizaciones y los directivos responsables de aspectos tales como la procuración de justicia, la asistencia social —dotación de servicios de seguridad pública, educación, salud, alcantarillado, entre otros- o la recaudación fiscal es más difícil, complejo y polémico dado su carácter sociopolítico, que el manejo de una organización que construye coches, computadoras o que comercializa seguros de vida.

Las organizaciones públicas se diferencian de las privadas, entre otros aspectos, en términos de su perspectiva del tiempo, las medidas de su funcionamiento, necesidades y perspectivas laborales del personal, equidad, pero sobre todo por la legitimidad de sus acciones: en la administración pública no basta obtener resultados, es imperante que las políticas públicas y los programas se implementen en términos de legitimidad del desempeño gubernamental y bajo estricto apego al marco normativo, ya que un funcionario público no puede hacer más que lo que la ley estrictamente le faculta, en cambio, los empresarios pueden actuar en tanto la ley no se los prohíba.

Por otra parte, el contexto de las empresas privadas es comercial, en tanto que la naturaleza de las organizaciones públicas es política y social, y como consecuencia de esta dimensión sociopolítica de sus trabajos, ${ }^{5}$ los administradores públicos tienen una perspectiva de planificación acotada por el tiempo en que están en los cargos, principalmente los de elección pública y, por lo tanto, se reducen las posibilidades de hacer una planeación que garantice la continuidad de sus trabajos en el largo plazo; asimismo, existe una mayor diversidad y transformación de las expectativas comunitarias, las medidas de funcionamiento pueden ser vagas, es decir, más cualitativas (intangibles) que cuantitativas, en ausencia de un contexto que determine claramente los beneficios asociados a las iniciativas o de las cuotas de mercado, ejemplo: es más fácil medir la calidad del funcionamiento y los beneficios monetarios de comercializar un refresco de cola, que

4 Esta es una visión en la que trascienden más los resultados que los programas: dentro de los propósitos de administración policial, no se analiza aisladamente el trabajo realizado por la policía, los programas que se han implementado o la adquisición y disposición de mejor armamento o tecnología, lo que cuenta es obtener impactos que puedan ser comprobados y verificados empíricamente: la disponibilidad de sociedades seguras y protegidas, que las personas se sientan y estén seguras, ya que se propició una reducción de la incidencia delictiva.

5 Una característica de los sistemas políticos democráticos es la facultad de la ciudadanía de votar y ser votados para cargos públicos, lo cual implica la alternancia en el poder, por lo tanto, los periodos de las gestiones son necesariamente acotados en el tiempo, esto es distinto en la administración empresarial. 
analizar la calidad y trascendencia de aprobar una ley — así como su justa implementación y administración-, o calcular el costo-beneficio de adquirir una flotilla de patrullas.

Lewis Gunn establece algunos aspectos que sirven para diferenciar entre las actividades de la administración pública —incluidas las funciones de seguridad pública y el trabajo de la policía—, respecto a las privadas:

1. “...La administración pública es sustancialmente diferente a la privada" (Gunn, 1987); algunos elementos que establecen estas diferencias son: la delimitación legal de los campos de actividad, el monopolio de ciertas sanciones y poderes coercitivos - el uso de la fuerza es exclusivo del gobierno-, y un entorno de desempeño mucho más complejo y variado de la función pública. Particularmente, la policía enfrenta situaciones de riesgo en sus actividades de campo que ningún manual de procedimientos, por más elaborado que sea, puede prever, limitándose a considerar criterios generales de actuación, en comparación, una empresa privada sólo puede obtener una certificación de calidad si su funcionamiento se apega a manuales que predefinen su desempeño.

2. “...La administración pública y la privada se parecen en los aspectos no importantes" (Gunn, 1987). Pese a las aparentes coincidencias de los mecanismos de gestión de las entidades públicas y privadas, los contextos político y comercial definen, para ambos casos, visiones diametralmente distintas. Las técnicas de gerencia privada pueden ser útiles en el sector privado, pero no garantizan el éxito en las organizaciones gubernamentales: el contexto social determina el trabajo de la policía, y si las visiones comerciales de la gerencia empresarial son exportadas sin las adecuaciones necesarias de sensibilidad social requerido para la hechura de las políticas públicas y los programas correspondientes, el establecimiento de metas y las valoraciones serán erróneas, ejemplo: para una autoridad municipal, la valorización financiera del costo-beneficio de comprar una patrulla es bajo o nulo, ya que no representa ninguna entrada directa de ingresos - el retorno de la inversión-, ${ }^{6}$ por lo tanto, no se recuperan las erogaciones, pero el costooportunidad es alto, ya que de no contarse con vehículos de patrullaje, aumentará la inseguridad de la comunidad, ya que la policía carece de un recurso elemental para su trabajo.

3. “...El Management Público es un paradigma integrador” (Gunn, 1987). El enfoque de gestión pública retoma la experiencia de la administración empresarial, pero al mismo tiempo ha desarrollado sus propios conceptos y herramientas de gestión específicas para las organizaciones del

6 De realizarse el cálculo de la Tasa Interna de Retorno (TIR) de la adquisición de patrullas o chalecos antibalas, un administrador financiero podría concluir que, desde el punto de vista exclusivamente financiero, éstas son inversiones no rentables ni productivas, por lo que de aplicarse esta lógica, estas compras no se realizarían y la policía — así como el total de las instancias del Estado — terminarían no adquiriendo nada. 
gobierno, considerando que los problemas públicos son específicos, como los que enfrenta una corporación policial; es en este sentido que se establece la necesidad y urgencia de proponer un concepto de administración policial, los elementos que lo componen, así como temáticas y procedimientos específicos asociados a la actuación de las policías. ${ }^{7}$

Las corporaciones policíacas no son solamente diferentes de las organizaciones privadas sino también de otras organizaciones públicas en vista de los conflictos que generan la función policial en sociedades democráticas. ${ }^{8}$ Roberg (2002) considera que la policía ejerce acciones que sectores de la sociedad no desean, como las multas de tráfico y los arrestos, pero que son necesarias para la convivencia y la gobernabilidad. Pese a que se tiene un acuerdo ciudadano para ser gobernado, en la práctica, las personas a menudo se oponen a la intervención del Estado pese a que teóricamente los gobiernos democráticos representan y sirven a los ciudadanos que los eligieron; en este sentido, un gobierno democrático se basa en el consenso entre los habitantes y el gobierno, pero en el caso de que estos acuerdos fallen, el policía, al representar tanto al gobierno como a la sociedad, entra en un conflicto de intereses: ¿debe obedecer a la autoridad o apoyar a la sociedad que representa?

El análisis académico de la función policial es indispensable para emprender procesos de reforma sostenidos, que conduzcan hacia un desempeño policial ejercido en términos democráticos. A pesar de la insuficiencia en la formalización del marco teórico y académico, la medición de la confianza de la sociedad respecto al cumplimento de las tareas policiales, confirma que el desempeño policial en México está en crisis: existe un histórico distanciamiento entre la forma en que la policía ejerce su mandato y sus atribuciones, respecto a lo que la sociedad espera de ellas.

Los enfoques gerencialistas de la Administración Pública (gerencia pública y new public management) tienen la pretensión de despolitizar a la función gubernamental, incluyendo en ello el trabajo de la corporación policial, así como de cada uno de sus actores, reduciéndola a sólo procesos administrativos. El actual reposicionamiento y revaloración de lo político de la administración pública recupera la congruencia del proceso de consolidación democrática del país: la función pública debe ser ejercida en procesos integrales, no sólo enmarcados en parámetros racional-instrumentales, sino en términos de legitimidad y aceptación social.

Es así que el análisis administrativo del trabajo de la policía requiere transitar hacia enfoques donde se revaloren las perspectivas política y ciudadana: el vínculo del gobierno con los ciudadanos es de naturaleza política, es una relación

7 En general, las policías al estar facultadas para el empleo de la fuerza, las diferencia de las otras instancias de gobierno, y en lo particular, temas como la supervisión policial, el control, las averiguaciones y la atención de quejas del desempeño policial, que tienen contextos y procedimientos específicos y los diferencian de otros programas públicos.

8 Las funciones de la policía son claramente más propicias de ser cuestionadas en las sociedades democráticas, por la naturaleza misma de esta visión política, respecto a formas de gobierno no democráticas: la propuesta presentada en este trabajo, busca fundamentar un modelo de administración policial democrática. 
gobernante-gobernado y es determinada por el ejercicio del poder, por lo tanto, el ciudadano no es un consumidor de los productos y servicios que el gobierno "coloca en un mercado", ya que esto implicaría una relación entre oferente y demandantes, es decir, un vínculo económico-comercial.

El verdadero desafío de una policía democrática está en la formación de oficiales que incorporen una lectura sensible de la sociedad en la que viven y de la función que representan. De esta manera, una agenda de estudio público administrativo de la función policial, debe de realizarse desde diversas perspectivas de análisis, tales como:

- La definición del tipo de arreglo institucional que posibilite la viabilidad de la implementación de un modelo de policía democrática.

- En una estructura organizacional predefinida, ¿cómo se determina el comportamiento de los policías y cómo se toman las decisiones?

- Desde lo administrativo, ¿cuáles son las capacidades y herramientas que deben emplear las policías para incrementar las probabilidades de que cumplan con su mandato institucional?

- La formalización académica del estudio de la función policial, lo cual implica la determinación, el análisis, tratamiento y formulación científico-teórico del objeto de estudio.

- ¿Cómo es el proceso y estrategias de cambio administrativo, organizacional e institucional de las policías?

- El desempeño de la policía como ejercicio de gobierno: procesos pragmáticos de implementación-aplicación de lo teóricamente integrado, correspondiéndole por lo tanto a esta función, atender las demandas sociales de seguridad ciudadana.

La agenda de trabajo de la administración policial busca conferir a las policías capacidades de desempeño y de eficiencia, incidiendo en las dinámicas de gobernabilidad y desarrollo de los Estados: el desempeño policial no se agota en sí mismo, tiene un referente mayor definido por el desarrollo socioeconómico y político de los Estados, y de ahí su viabilidad.

\section{LA ADMINISTRACIÓN PÚBLICA Y POLICIAL}

Siendo evidente el carácter público del trabajo policial, la determinación y análisis del manejo de las corporaciones policiales se define a partir de los conceptos de la Administración Pública. ${ }^{9}$ Busca darle a la policía las capacidades para cumplir con su mandato, utilizando para esto herramientas y técnicas administrativas.

Cualquier administrador público, incluidos los directivos policiales, deben de tener la capacidad de:

9 El análisis de la actuación policial, así como de cualquier política pública es multidisciplinar y por lo tanto puede ser abordado desde diferentes perspectivas: legal (derecho), eficacia y eficiencia (económico-administrativo), función social (antropología-sociología) o en términos políticos. 
- Usar eficaz y productivamente sus recursos.

- Ser eficiente en la función directiva. El mandato institucional de la policía establece qué se debe de hacer, el cómo, se define a partir de la administración policial, y es responsabilidad de la dirección la implementación del mandato.

- Motivar al personal en función del cumplimiento del mandato y los objetivos institucionales.

- Desarrollar una cultura organizacional centrada en los valores que justifican la creación y existencia de la corporación policial.

- Desarrollar un ambiente laboral que premie la excelencia y constante desarrollo de las capacidades de sus elementos: generar el capital humano de la corporación.

- No debe ser especulativo. Desde el punto de vista de la policía, el fundamento legal de su mandato debe ser explícito, estableciendo claramente tanto los resultados esperados como los procedimientos para conseguirlos.

- No deben confundirse desempeño policial con represión: la policía no debe generar temor ni en la sociedad, ni en el mismo personal policial. Para la administración policial, los temas de control y supervisión deben entenderse como estrategias de aprendizaje que contribuyan al desarrollo de los policías y el mejoramiento de su actuación, y no como un mecanismo inhibidor/sancionador.

- Una responsabilidad fundamental de la administración pública es la creación de un clima organizacional que favorezca la innovación, lo cual sólo puede conseguirse con la capacitación y el aprendizaje continuo.

El manejo de las corporaciones de policía en particular y de la administración pública en general, tienen que ver con "...la conducción de las capacidades humanas del personal adscrito a una organización” (Lynn, 1990). Los encargados de las policías son directivos que deben trabajar bajo premisas de servicio público y estar conscientes de que su desempeño enfrenta tanto el reconocimiento como la descalificación social, por lo tanto, deben propiciar que agentes de policía y personal de apoyo administrativos estén conscientes de la trascendencia social de sus actos. De ahí la importancia de una administración policial orientada a la consecución de impactos, ya que obliga a directivos y operadores a participar en la definición de los programas de trabajo, sensibilizarlos respecto a la importancia de sus logros en términos de su incidencia en el propósito de construir y disponer de sociedades seguras.

Las corporaciones de policía no son organizaciones que consumen recursos sin ningún resultado, pero la valoración y trascendencia de su actuación no debe medirse por criterios de costo-beneficio o por medidas industriales de productividad (cálculo de la relación producción respecto a los recursos y tiempo utilizados), ${ }^{10}$

10 Es complejo aplicar los criterios de productividad a una corporación policíaca: ¿la policía es más productiva por haber detenido a un mayor número de delincuentes, por disminuir su empleo de recursos, por propiciar una sociedad más segura o por ser menos corrupta? En cualquier caso, existen problemas para cuantificar 
ya que en general, los resultados de la función pública deben considerarse como positivos en función de su aporte a la gobernabilidad de los Estados, por su incidencia en el incremento del bienestar general o malos si lo perturban o deprimen, de esta manera, el análisis del manejo de los recursos financieros debe realizarse por criterios de:

1. Costo-impacto. Valoración de la relación de presupuesto ejercido respecto a la verificación de los impactos obtenidos, ejemplo: la medición de la incidencia y trascendencia de la adquisición de patrullas, armamento, recursos informáticos y de comunicación, en la disminución de las probabilidades de que se cometa un delito o un acto violento.

2. Costo-oportunidad. El análisis de la afectación de las condiciones de seguridad pública por no adquirir o contar con herramientas de trabajo como patrullas, equipamiento, sistemas informáticos o no incrementar el sueldo de los oficiales.

La policía debe asumir que su mandato institucional forma parte de un proyecto de nación, como un componente de la política de seguridad — la cual a su vez es un elemento de la política criminal - y que, por lo tanto, su actuación se valorará por su aporte a la seguridad y protección de la sociedad. En la medida que el desempeño policial incida o no en el cumplimiento de la política de seguridad pública, se valorará la eficiencia de su actuación.

Debe considerarse que el trabajo policial, y en general el que realiza cualquier entidad del sector público, no se limita a la ejecución de un mandato, sino que debe tener como perspectiva, como analiza Cohen (2005), lograr resultados que satisfagan aspiraciones comunes de una sociedad; en este sentido, las autoridades políticas elegidas y los funcionarios públicos designados, deben estar plenamente conscientes de las responsabilidades sociales que asumen, por lo tanto, esta manera de presentar a la administración policial y pública, conduce a nociones de transparencia y rendición de cuentas.

\section{MODELO DE ADMINISTRACIÓN POLICIAL PARA REGÍMENES DEMOCRÁTICOS}

La función policial en democracia, debe ser entendida y ejercida como un sistema de respuestas que anteponen las corporaciones de policía, para atender las necesidades y resolver los problemas de seguridad de los ciudadanos.

Los términos de referencia para el manejo de las corporaciones de policía, se integran fundamentalmente por tres elementos:

a. Componente político. Función policial desempeñada en función de esquemas de toma de decisiones y procedimientos social y democráticamente validados. Vinculado el ejercicio gubernamental para la creación

estos criterios y por lo tanto el cálculo de la productividad policial se relativiza, pero esto no implica que no se deban realizar ejercicios para tratar de establecer criterios paramétricos mesurables del trabajo policial y generar indicadores asociados al desempeño. 
de sociedades seguras y libres de riesgo, la política pública de seguridad establece los parámetros de legitimidad del trabajo policial: la forma en que las corporaciones de policía ejercen sus facultades y cumplen con su agenda programática de trabajo.

Las policías están facultadas legalmente para el empleo de la fuerza, y este atributo las haces sustancialmente distintas de cualquier otra instancia gubernamental, de esto que se requieran categorías propias para el análisis administrativo de las corporaciones de policía: es diferente administrar una escuela o un hospital públicos que una policía.

Categorías de análisis de la legitimidad de la función policial: establecimiento de los derechos humanos como el principal referente del trabajo de la policía, ciudadanización policial, transparencia y rendición de cuentas, y supervisión civil externa.

b. Componente legal. El trabajo público administrativo debe realizarse a partir de un estricto apego a la ley. Implica la verificación del sustento legal del desempeño policial.

Categoría de análisis: Legalidad

c. Componente administrativo. Función policial eficaz y eficiente en el cumplimiento de su mandato institucional, y con un desempeño orientado a la obtención de impactos en términos de la incidencia del trabajo de la policía en la disminución de la probabilidad de que se cometan delitos, y que los impactos obtenidos puedan verificarse empíricamente.

Categorías de análisis: eficiencia/eficacia del desempeño, el cual debe orientarse a la consecución de impactos, no al cumplimiento de metas.

Esquema 1

Modelo de Administración Policial para Regímenes Democráticos

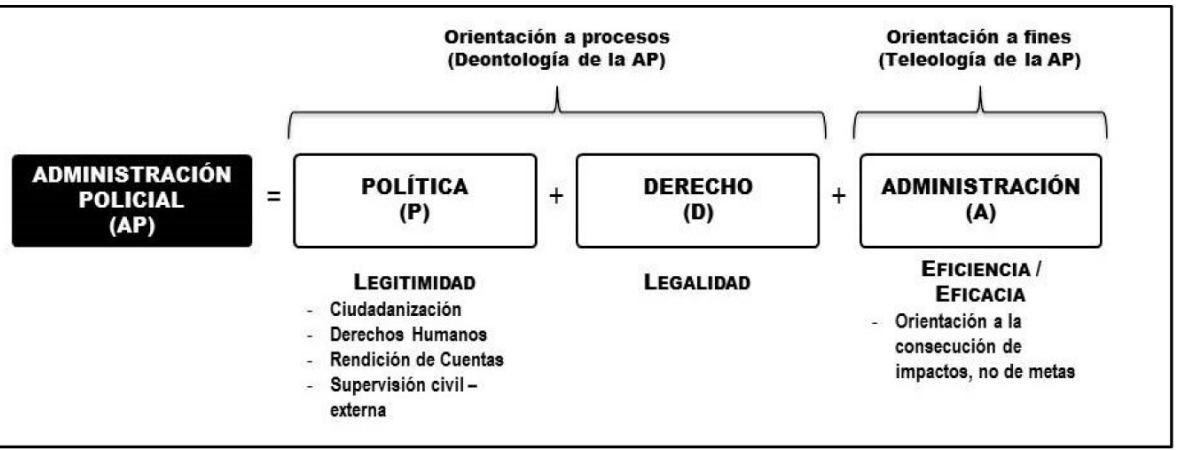

Fuente: Elaboración propia.

Del anterior cuadro, el presente trabajo propone lo siguiente:

a. La administración policial es un fenómeno determinado y compuesto por una dimensión Política (P), una de Derecho (D) y otra Administrativa (A). 
b. La deontología ${ }^{11}$ de la administración policial, establecida como los referentes de actuación y desempeño que deben observar las corporaciones de policía, el bien hacer de la policía, está determinado por su legitimidad y su legalidad.

c. Legitimidad. El desempeño de las policías está directamente asociado con el ejercicio del poder gubernamental al ser éstas parte de éste y no poder disociarse de él: todo acto de la administración pública, incluyendo a los que realizan las corporaciones de policía, es un acto político y por lo tanto su ejercicio, su praxis, debe legitimarse. Esta legitimización se asocia directamente por la forma en que se da el desempeño policial. Así mismo, esta legitimidad está parametrizada por los siguientes elementos:

- Ciudadanización de la función policial: implica que el principal criterio de actuación de los policías debe ser atender las necesidades de seguridad de las personas, supeditando el criterio actual de las corporaciones de acatar las instrucciones del mando.

- Ampliar y mejorar los mecanismos y espacios de interlocución ciudadano y policías: que ambos actores se reconozcan como interlocutores válidos.

d. Legalidad. Todo acto público administrativo depende de un marco jurídico que faculta a los funcionarios a actuar, y así mismo, establece los límites y criterios de esta actuación; de esta manera, cualquier proceso que realice la policía por fuera del marco normativo, es ilegal y debe sancionarse.

e. La teleología ${ }^{12}$ de la administración policial, es la orientación a impactos, esto implica que el trabajo de la policía no es una actividad sin propósitos ni metas, ya que incide en la función gubernamental de resolver los problemas de inseguridad y atender las demandas de protección sociales. Esta orientación a fines, al realizarse considerando medios finitos, le da el carácter administrativo al trabajo de la policía.

11 La deontología es un término introducido por Bentham en Deontología o la ciencia de la moralidad (1889), y se refiere a la rama de la ética cuyo objeto de estudio son los fundamentos del deber y las normas morales. De esta manera, es el conjunto ordenado de deberes y obligaciones morales que tienen los profesionales de una determinada materia. También conocida como "teoría del deber", junto a la axiología, es una de las dos ramas principales de la ética normativa.

Para la administración policial, implica las categorías analíticas a considerar, que determinan un desempeño democrático o no.

Cfr.: http://www.deontologia.org/, consultado el 05 de marzo de 2015

12 Teleología proviene de los dos términos griegos_Télos_(fin, meta, propósito) y_Lógos_(razón, explicación), por lo que teleología_puede ser traducida como «razón de algo en función de su fin», o «la explicación que se sirve de propósitos o fines». Decir de un suceso, proceso, estructura o totalidad que es un suceso o un proceso_teleológico_significa dos cosas: a) que no se trata de un suceso o proceso aleatorio, o que la forma actual de una totalidad o estructura no es (o ha sido) el resultado de sucesos o procesos aleatorios; b) que existe una meta, fin o propósito, inmanente o trascendente al propio suceso, que constituye su razón, explicación o sentido. En términos de cierta tradición filosófica, esto equivaldría a decir que dicha meta o sentido son la razón de ser del suceso mismo, lo que le justifica en su ser.

Cfr.: http://www.mercaba.org/DicPC/T/teleologia.htm, Consultado en 05 de marzo de 2015. 
f. El trabajo de la policía si bien está orientado a la consecución de impactos, no implica que la manera de conseguirlos sea el criterio primordial que defina el total de los procesos decisionales relacionados, si no que la lógica de este proceso decisional debe ser legítimo y legal, esto implica que en el trabajo de la policía los fines no justifican los medios, y al tratarse de un fenómeno político-gubernamental que implica el uso de la fuerza, la legitimidad de los procesos es más importante que la consecución de fines.

g. El análisis integral del desempeño policial, está determinado por los niveles de legitimidad, legalidad y eficiencia/eficacia de la forma en que se desempeña. La administración policial es la responsable de garantizarlo.

\section{HACIA UN CONCEPTO DE ADMINISTRACIÓN POLICIAL}

Las funciones de los directivos y encargados de administrar una corporación policial, incluyen su diseño organizacional, la planificación del trabajo operativo y administrativo, el establecimiento de metas, atendiendo las expectativas y necesidades sociales asociadas al trabajo de la policía.

Tanto la organización como los empleados, es decir, los directivos y los encargados, tienen expectativas unos respecto a los otros: la organización espera que los empleados realicen eficientemente las tareas que tienen asignadas y que las realicen respetando el mandato legal de la policía, aprendiendo nuevas habilidades, tomando iniciativas, y en la medida de lo posible, siendo capaces de trabajar independientemente. A su vez, los empleados esperan que la organización los trate bien, dignamente y les proporcione el salario, las ventajas y condiciones de trabajo que propicien su éxito profesional.

Harmon define a una organización como "...una agrupación social de dos o más personas" (1999: 25), las cuales funcionan coordinadamente para alcanzar metas comunes preestablecidas. Es en este sentido que el propósito de la administración es trabajar hacia el cumplimiento de las metas organizacionales, considerando que las necesidades tanto de los empleados como de la sociedad e incluso de otros individuos y organizaciones, son cambiantes, por lo que una de las responsabilidades básicas de los administradores públicos es trabajar hacia la integración y conciliación de expectativas y necesidades colectivas, organizacionales e individuales.

El análisis del trabajo de las organizaciones policíacas, de cómo sus empleados se desempeñan, tanto los directivos como los oficiales, y la integración de herramientas y estrategias de administración que posibiliten un manejo eficiente de la corporación que posibilite cumplir con su mandato, conforman el contexto para proponer un concepto de administración policial:

La aplicación de los referentes de la ciencia Administración Púbica al manejo de las corporaciones de policía, con el propósito de cumplir con su mandato institucional y realizar un desempeño policial en términos de legitimidad (componente político), legalidad (componente jurídico), y eficiencia/ 
eficacia (componente administrativo), buscando incidir en la construcción de sociedades seguras, protegidas y libres de riesgo.

Esta capacidad de gestión debe realizarse en un contexto de racionalidad, misma que la organización policial y sus directivos adquieren del conocimiento estructurado y disponible de la disciplina Administración Pública, así como por el consenso, ya que éste es un elemento fundamental del enfoque de políticas públicas, debido a que el ejercicio gubernamental debe ser ejercido con legalidad, legitimidad y eficiencia-eficacia. En este sentido, consenso en el contexto de administración policial deberá entenderse como la convergencia y conciliación de intereses tanto de la sociedad a la que la policía sirve, de las autoridades locales y federales, respecto a los de la corporación policíaca y sus empleados, ya que se trata de una sociedad democrática.

\section{LA ADMINISTRACIÓN POLICIAL EN DEMOCRACIA}

El siguiente cuadro ilustra la organización y funcionamiento de la administración policial. Propone que los parámetros que definen la función de la policía son: 1) Legitimidad y consenso, validación social del trabajo de la policía, implica el respeto a los derechos humanos, justificación y racionalidad en el uso de la fuerza, transparencia y rendición de cuentas, y un servicio policial orientado a la solución de necesidades ciudadanas de seguridad, 2) Legalidad, el trabajo policial se debe realizar con estricto apego a la ley, y 3) Eficiencia, función policial orientada a la consecución de resultados verificables empíricamente.

En el centro del sistema se ubica la administración policial, la cual tiene como temas específicos correspondientes el ciclo administrativo: planeación, diseño organizacional, dirección-control y evaluación. Estos apartados son implementados a partir de los subsistemas correspondientes, particularmente, los subsistemas de rendición de cuentas y de información son fundamentales para la policía, ya que, desde el punto de vista de una reforma policial, cumplen con dos valores de entidades públicas en sociedades democráticas: la transparencia y la rendición de cuentas. Por otra parte, estos procesos son integrales, transversales e inciden en todas las funciones de la corporación. 
Esquema 2

\section{Sistema de la Administración Policial en Democracia}

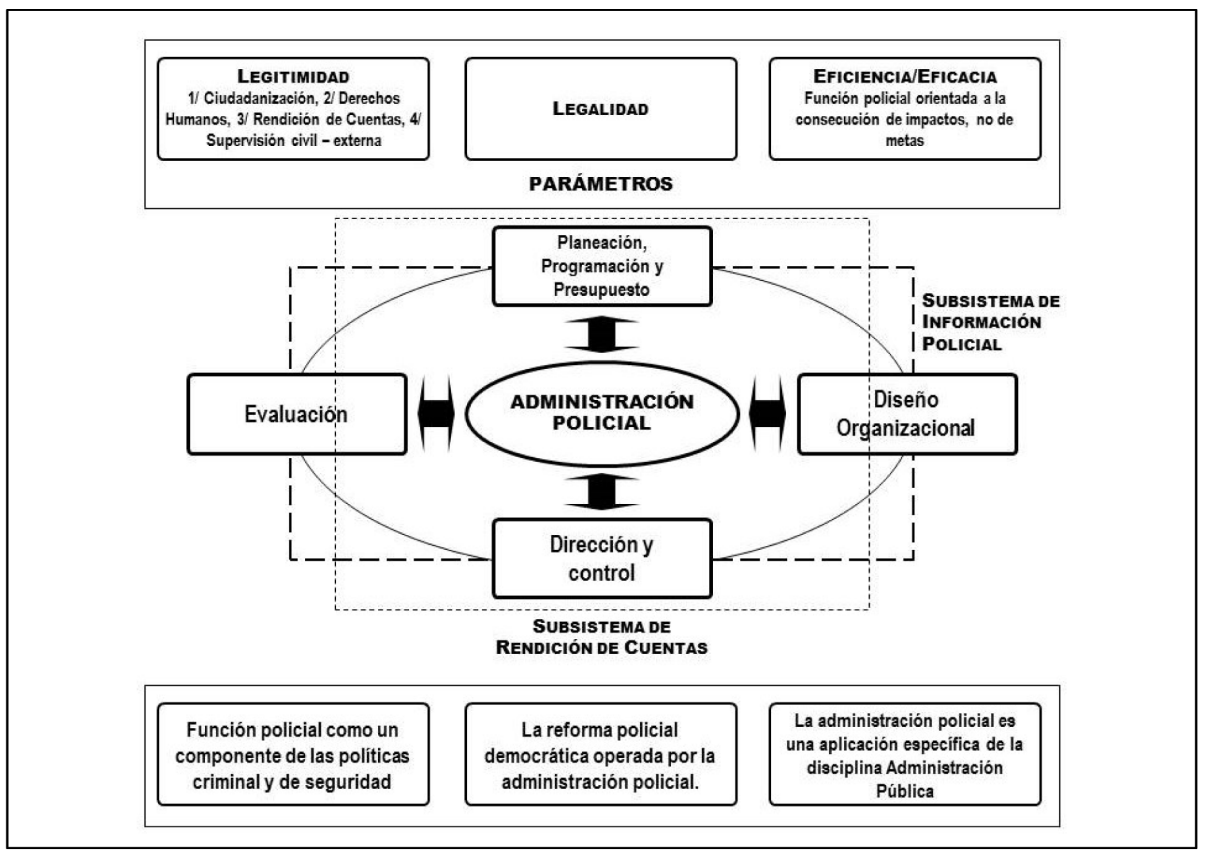

Fuente: Elaboración propia.

La función policial conlleva temas específicos de una corporación policíaca: actuación policial en clave de derechos humanos, la supervisión, el control policial, la atención de quejas del desempeño policial, la academia de policía, respeto irrestricto a la ley, uso legítimo de la fuerza y carrera policial, entre otros temas.

En la base del sistema se presentan los criterios referenciales, que se utilizaron para arribar al concepto de administración policial, el cual tiene como antecedente directo, la demanda social de diseñar e implementar las políticas criminal ${ }^{13}$ y de seguridad pública, los parámetros de la reforma policial democrática, y la aplicación de los elementos teóricos de la ciencia de Administración Pública al manejo de las corporaciones de policía.

13 La política criminal es el conjunto sistemático de los principios fundamentales basados en una investigación cientifica de las causas de los delitos, las conductas violentas y de los efectos de la pena, lo cual en su conjunto deriva en medidas tanto preventivas como punitivas tomadas por los Estados para atender los fenómenos de la criminalidad y las violencias, reconociendo las medidas preventivas como aquellas empleadas para que los miembros de la sociedad no tengan la oportunidad de incursionar en la criminalidad. Tiene las siguientes funciones: 1/ Seguridad pública encargada de la prevención del delito, así como de garantizar y construir la paz y el orden público, 2/ Procuración de justicia, y su incidencia y responsabilidad directa en el abatimiento de la impunidad y en la impartición de justicia, y 3/ Readaptación social de los sentenciados (sistema penitenciario). 


\section{Funciones de la administración policial}

1.1 Función de planeación, programación y presupuesto. Área de la administración policial encargada de establecer los objetivos y metas institucionales, así como las correspondientes asignaciones presupuestales y programación de tareas, considerando actividades propias de una corporación policial como la supervisión, el control o la investigación.

Es la función técnica de la administración policial y debe estar reflejada en el organigrama en una subdirección técnica, de planeación o similar, donde se definan las líneas de trabajo requeridas para cumplir con la agenda programática (Sánchez, 2003).

1.2 Función de diseño organizacional. La organización es la determinación de funciones, responsabilidades, reglas y normas de comportamiento de un conjunto de áreas, departamentos y cargos, lo que permite regular las funciones de los miembros adscritos a una entidad. La organización es reflejada en la estructura organizacional. De esta manera, el subsistema de organización de la policía posibilita cumplir con sus metas, objetivos, con el mandato legal e instrumentar el plan y programa de trabajo.

El diseño de la estructura de la organización, del sistema de trabajo, los arreglos de trabajo grupal y las asignaciones individuales de tareas, deberán realizarse conforme a esta estructura organizativa (Harmon, 1999).

1.3 Función de dirección - control policial. Proceso por el cual los encargados de esta función dentro de la corporación - generalmente los directivosdeterminan:

- Las estrategias para que la calidad de los diferentes sistemas y servicios de la organización pueden mejorarse.

- Si se está cumpliendo o no con las metas y objetivos institucionales establecidos.

- Si el desempeño institucional es congruente con el programa y los planes de trabajo.

- Si los oficiales siguen las políticas y los procedimientos de la organización.

Los aspectos de eficiencia y eficacia, así como los referentes de cantidad y calidad son los criterios de control de esta función de la administración.

Si las metas o los objetivos no se están alcanzando, si los planes, las políticas y los procedimientos no se están siguiendo, o se ha detectado un problema de desempeño en el servicio de la organización - principalmente respecto a los derechos humanos - , los responsables deben establecer las razones y determinar las acciones de corrección. El controlar puede ser la función directiva más problemática por las dificultades que enfrenta el responsable para detectar las fallas del sistema o las razones de un servicio inadecuado, así como también el diseño de las estrategias para cambiarlas y mejorarlas. Por ejemplo, la corrupción y el mal 
uso de la fuerza de la policía continúan siendo serios problemas de desempeño, pese a los esfuerzos por analizar sus causas y corregirlas.

1.4 Función de evaluación del desempeño policial. Constituye el proceso de análisis del rendimiento integral del desempeño policial, tanto de la corporación como un agregado, como de cada función particular que realiza la policía. Considera que la mayor parte de los policías procuran retroalimentarse de la manera en que cumplen sus funciones, por lo que los comandantes y oficiales con personal a su cargo deben evaluar el desempeño particular de cada oficial para decidir las acciones que deben tomar; en este sentido, la evaluación informal, basada en la observación del trabajo diario, es necesaria pero insuficiente si se pretende que la evaluación opere como un mecanismo de aprendizaje organizacional. La evaluación determina la brecha existente entre lo planificado respecto a lo realizado, e implica que la policía argumente y justifique la existencia de dicha diferencia, produzca una constancia o referencia formal de su trabajo y aprenda de su propia experiencia.

Dentro de la administración policial, el subsistema de evaluación formaliza y sistematiza el proceso de retroalimentación de toda la administración de las policías: a) desempeño, b) análisis, c) detección de problemáticas, y d) sugerencias, con el cual los responsables pueden identificar a los agentes que cumplen o exceden lo esperado y a los que no lo hacen; también provee de información analítica a los tomadores de decisiones sobre promociones internas, compensaciones, y otras más del área del departamento de personal dependen de la información sistemática y bien documentada disponible sobre el policía.

La responsabilidad de esta función de la administración policial es realizar la evaluación del desempeño de cada oficial y de la corporación en su conjunto, responder a la necesidad de sistematizar y definir los criterios y políticas de la corporación respecto a la evaluación. Cano (2004) indica que, pese a que es necesario desarrollar enfoques de evaluación diferentes para los directivos, el personal de mando, de apoyo y los policías, es conveniente tener criterios congruentes al interior de cada categoría para obtener resultados útiles.

1.5 Función de supervisión policial. El área de supervisión interna, la policía de la policía, “...es una instancia importante de defensa contra la corrupción, el abuso policial y la violación de derechos humanos" (Peak, 2004). El que esté constituida como un área que figura en el esquema organizativo de una corporación, es indicador del grado de voluntad de las autoridades policíacas para premiar y replicar actuaciones efectivas, responsabilizar y sancionar al personal por comportamientos negativos o incidentes de abuso, así como para delimitar funciones investigativas especializadas al interior de la policía ante denuncias de abuso policial.

El subsistema de supervisión interno de una corporación policíaca tiene como propósito general regular y orientar las actividades cotidianas de la institución, tratando de evitar desvíos de lo programado en términos del mandato institucional, reducir los casos de abuso policial, y colaborar en el análisis y la transformación 
de los procedimientos, los sistemas de administración y regulación, esto permite fortalecer las capacidades policiales, mejorar el desempeño, la eficacia y elevar la conducta ética.

\section{A El subsistema de rendición de cuentas policial}

El objetivo del subsistema de rendición de cuentas dentro del enfoque de la administración policial es propiciar y contribuir a la transformación cualitativa de la actuación de la policía, fundamentando y ordenando la reforma de una policía convencional hacia una que ejerce sus obligaciones y praxis en términos democráticos. Esta transformación es efecto y consecuencia de una revisión profunda de los procedimientos de desempeño policial, los alcances y propósitos de su actuación, los cuales están definidos por los marcos legales y por la relación Sociedad-Gobierno-Policía.

Con la implementación de un sistema de control de esta naturaleza, se pretende que los resultados y logros se concreten en el mejoramiento de los órdenes de convivencia social, en la disminución de los índices de delincuencia, en desempeños policiales apegados a derecho, en un trabajo policial que atienda antes que nada las necesidades de la ciudadanía, que tenga como referente fundamental los derechos humanos, oriente la actuación de la policía hacia una servicio transparente y "...examinar, supervisar e incluso burocratizar la discrecionalidad, para así asegurar que, de modo cotidiano, los agentes estén haciendo lo que esperamos de ellos, no lo que tememos de ellos" (Varenik, 2005: 25).

La evaluación del desempeño policial, de los logros, resultados y repercusión social, constituye la oportunidad para saber en qué medida las instancias que tienen a su cargo la seguridad pública cumplen con los objetivos para los que fueron creadas. La generación de mecanismos de evaluación de su actuar, sistematizados en el subsistema de rendición de cuentas, permitirá mejorar a estas instancias y los resultados de sus proyectos, ya que si se desconocen los efectos de su actuación, no es posible analizar si éstos son positivos, negativos o neutros, y por lo tanto se imposibilita que las corporaciones aprendan de sí mismas, lo cual conlleva riesgos políticos, de legitimidad de la actuación del Estado, de gobernabilidad, e incluso impactos en lo económico y lo social.

Una segunda justificación de la necesidad y urgencia de que las corporaciones de policía trabajen bajo esquemas de rendición de cuentas, lo define la visión integral que le confiere un modelo de gestión sustentado en la administración policial, integralidad que parte de la interacción entre la planificación/programación de funciones, el diseño organizacional, la gestión de los proyectos y la evaluación del desempeño, elementos que se definen a partir del mandato legal propio de las corporaciones policíacas. Esta visión integral supone que la planificación se fortalece con la rendición de cuentas y considerando que la planificación es obligatoria y permanente, la rendición de cuentas también participa de esa doble condición, debiendo realizarse de manera obligatoria y permanente.

Tradicionalmente, el tema de rendición de cuentas tiene una connotación eminentemente fiscalizadora, aludiendo a los informes contables que presentan 
los administradores a los dueños de las empresas; en este sentido, el administrador era el responsable de la empresa, por eso, debía informar periódica y detalladamente del manejo de los recursos.

La administración policial al tratar que la policía funcione bajo criterios de legalidad, legitimidad y orientada a impactos, propicia que esta perspectiva de gestión condicione a los directivos de las corporaciones policíacas a considerar el proceso de rendición de cuentas como un mecanismo normal, rutinario y altamente beneficioso para la corporación por la perspectiva de control y evaluación permanente de las acciones.

Al exigírseles a las policías una mayor transparencia de su gestión, una demostración más precisa de sus logros y determinar claramente la brecha entre lo conseguido respecto a lo previsto en las metas establecidas, las cuestiones de rendición de cuentas, transparencia y evaluación de la calidad del desempeño, se convierten en aspectos fundamentales en materia de administración y actuación policial; es en este sentido que rendición de cuentas se consolida como el referente de actuación y evaluación del desempeño policial, función permanente y obligatoria.

Por otra parte, la actuación policial para ser verdaderamente eficiente, debe tener pleno reconocimiento y aplicación de los derechos humanos, por lo tanto, al tratar de establecer una definición de eficiencia policial se deben considerar criterios, valores y referentes de derechos humanos, siendo imposible concebir una actuación policial efectiva si los derechos humanos no se han respetado: no es suficiente detener a un delincuente, es imperativo que esta detención se haya realizado con pleno respeto y protección de los derechos humanos, y de no ser así, estaríamos ante casos de abuso policial. ${ }^{14}$

En este contexto, la rendición de cuentas de la actuación policial se establece en el centro de la conceptualización y análisis de su administración, ya que la gestión de la corporación policial debe tener como uno de sus máximos referentes los derechos humanos: al rendir cuentas de cómo se han realizado los procesos de planeación, organización, dirección y evaluación y de sus resultados, y cuáles han sido los criterios y parámetros de actuación, se deben identificar las formas en que los derechos humanos fueron y son protegidos.

\section{EL SISTEMA DE LA FUNCIÓN POLICIAL}

Al aplicar la lógica de sistemas al trabajo de la policía, se trata de comprender a la función policial como una serie de procesos orientados a la consecución de fines. Para definir e ilustrar el mecanismo de trabajo y definición de la función policial como un sistema, se utilizan las categorías insumos (inputs), procesos, productos (outputs) e impactos (outcomes) propios de la teoría de sistemas.

$\overline{14}$ En este punto resalta la importancia de la legitimidad y el consenso en la valoración del desempeño policial y su conducción (análisis sociopolítico de la actuación de los agentes de la policía), y no sólo centrar la evaluación del desempeño en parámetros de eficiencia y eficacia (enfoque gerencialista del desempeño policial). 
1. Insumos (Inputs). Acontecimientos y circunstancias del entorno sociopolítico, económico y cultural, específicamente los asociados a las dinámicas del delito y las conductas violentas, en tanto que estos definen la política de criminal, de seguridad y la correspondiente función policial, de prevención del delito, y de esta manera, su mandato institucional. Son las demandas y apoyos solicitados por la sociedad al gobierno en materia de prevención, seguridad y protección, de los cuales se encarga la policía y conforman su ámbito de actuación.

2. Procedimientos (Black Box). En la lógica de sistemas los procedimientos se describen como realizados en una Black Box ya que los actores ajenos o externos al sistema enfrentan problemáticas recurrentes para observar el proceso de toma de decisiones organizacionales, así como la dinámica del procesamiento de los insumos. Para la función policial implica la aplicación de la lógica de la administración policial: el proceso y lógica en que los encargados de manejo de las corporaciones de policía toman decisiones. La caja negra — la black box-, se evita al implementar sistemas funcionales de transparencia y rendición de cuentas policiales.

3. Salidas (Outputs). Es la función policial fundamentada por las decisiones y las acciones operativas: el desempeño policial. Organizan las consecuencias resultantes, no de las acciones del ambiente sociopolítico, sino del desempeño de la policía y los resultados de la política de seguridad.

4. Impactos (Outcomes). Función policial orientada a la consecución de impactos que puedan verificarse empíricamente, y no sólo el cumplimiento de las metas programáticas, en suma, el principal impacto es la disminución de las probabilidades de que se cometa un delito o un acto violento, son los resultados de la función policial y están directamente relacionados con el cumplimiento o no del mandato institucional. Determina la eficiencia del desempeño policial en términos de la diferencia entre lo inicialmente solicitado a la policía (inputs) respecto a lo alcanzado (outcomes).

En esta lógica, la administración policial es el vínculo entre los insumos y los productos del sistema de la función policial, es decir, los procesos de la policía.

Los inputs y los outputs/outcomes, entendidos los primeros como demandas y apoyo de la sociedad en temas de seguridad y protección, y los segundos como las decisiones, las acciones y resultados del trabajo policial, que se mueven en un circuito de retroalimentación (feedback loop).

El sistema en su conjunto permite a las autoridades identificar las demandas de seguridad de la sociedad, los inputs de la función policial, y a través de la administración policial, recibirlas, organizarlas y definir la agenda de servicios y tareas de la policía, en el contexto de las políticas criminal y de seguridad, logrando generar los outputs y outcomes del trabajo policíaco. De esta manera se da un flujo de inputs y outputs/ outcomes en el sistema en un movimiento constante de interacción, por lo tanto, la oferta de servicios de la policía no es la misma en el tiempo y se modifica en función de las demandas sociales. 
Si las autoridades policiales no satisfacen las demandas sociales (inputs), existen anomalías en el circuito, dificultando el flujo de las respuestas de la policía a las demandas y problemas sociales de seguridad, ocasionando que el sistema entre en tensión, sea disfuncional, y pueda entrar en crisis, por lo que las autoridades policiales y gubernamentales deben mantener la tensión baja, procurar la menor cantidad posible de interferencias, posibilitando la persistencia del sistema y que éste no se colapse (entropía organizacional).

\section{Esquema 3}

Teoría de Sistemas de la Función Policial

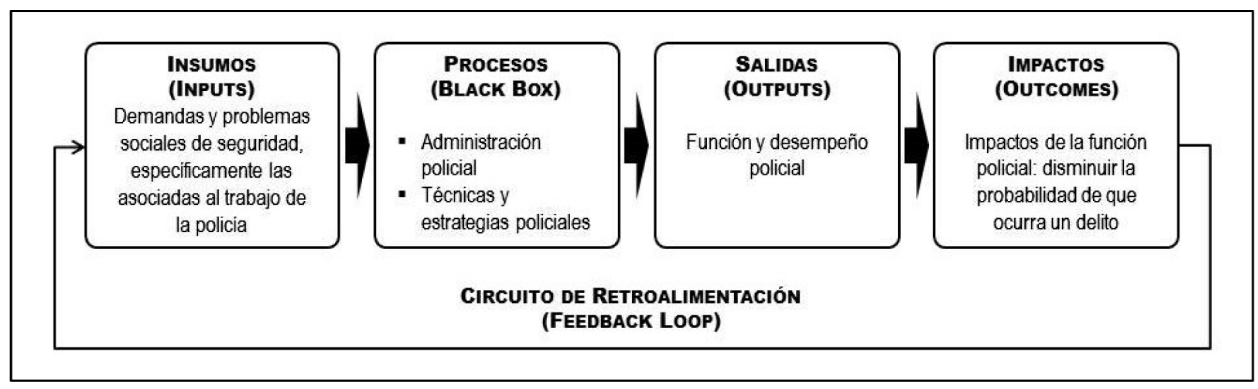

Fuente: Elaboración propia.

La administración policial se concibe como un sistema al estar integrada por actores, procesos y recursos, los cuales interactúan con un propósito específico: el cumplimiento del mandato institucional de la policía. Edgar Schein propone los siguientes aspectos necesarios en el diseño de una organización, partiendo de una visión de sistemas:

1. "La organización debe ser considerada como un sistema abierto" (Schein, 1988). Implica que la policía no sea una entidad autodeterminada y hermética: no es posible entender el trabajo de la policía bajo un modelo de organización cerrado, que no interactué con la comunidad a la cual sirve y protege, y que no define su agenda de trabajo como un servicio ciudadano.

2. "La organización debe ser concebida como un sistema con objetivos y/o funciones múltiples" (Schein, 1988). Pese a que el mandato de la policía es preciso, las tareas que realiza para cumplir este mandato son diversas: la prevención del delito, el control del tránsito, implementación de operativos de seguridad, arrestos y remisión de posibles delincuentes, entre otros.

3. "La organización debe visualizarse como constituida por subsistemas, los cuales están en interacción dinámica unos con otros" (Schein, 1988). En el modelo de administración policial que se propone, se identifican los siguientes:

- Subsistema de planeación, programación y presupuestación

- Subsistema de carrera policial 
- Subsistema de comunicación policial

- Subsistema de rendición de cuentas

- Subsistema de evaluación del desempeño policial

4. "Al estar integrada por subsistemas mutuamente dependientes, un cambio en uno de ellos, afectará a los demás" (Schein, 1988). La implementación de una cultura de la planeación y de rendición de cuentas, implica para las corporaciones policíacas toda una transformación de la manera de realizar su trabajo, ya que requiere de una profesionalización de los directivos y agentes, la planificación y programación de sus tareas, justificar cada una de sus acciones y, en general, considerar los elementos característicos de la reforma policial en democracia.

5. "La organización existe en un ambiente dinámico que interactúa con otros sistemas" (Schein, 1988). La definición del mandato policial a pesar de tener una continuidad en el tiempo, se modifica en función del ambiente político, social y económico, y a su vez afecta a cada uno de estos aspectos y su mismo entorno: la actuación de la policía modifica y es modificada por su contexto.

\section{CONCLUSIONES}

El contexto, procedimientos y estrategias de la administración pública son sustancialmente distintos a los de la administración privada y comercial.

Por su carácter eminentemente público y social, y sobre todo por ser una organización del Estado, los términos y procesos de la administración policial se definen a partir de los elementos y el conocimiento teórico consolidado y disponible de la ciencia de la Administración Pública.

La función policial está integrada por tres dimensiones: 1) Política. Implica que el trabajo de la policía debe ser legítimo, considerando un respeto irrestricto e innegociable de la protección de los derechos humanos, funcionalidad de sistemas de transparencia y rendición de cuentas, ciudadanización de la función policial y la permisibilidad de la evaluación de instancias externas y civiles de la función policial, 2) Derecho. Desempeño policial legal y de estricto apego a la ley, y 3) Administración. Implica la eficiencia y eficacia del trabajo de la policía, así como un desempeño orientado a la consecución de impactos que puedan verificarse empíricamente.

La administración policial busca transferirle capacidades de gestión a las corporaciones de policía y sus actores para ejecutar los lineamientos programáticos de su agenda de trabajo, generando el conocimiento organizacional que puede ser utilizado continuamente para cumplir con su mandato, mejorar la satisfacción del servicio y el desempeño de la organización policial.

Analizando la función policial desde una lógica de sistemas, el trabajo de la policía constituye la serie de respuestas (outputs/ outcomes) que presenta el gobierno a las demandas sociales de seguridad (inputs). De esta manera, la administración policial constituye los procesos requeridos para generar y articular dichas 
respuestas. La administración policial organizada desde una perspectiva de sistemas, implica que en ésta interactúan y convergen distintos elementos, procesos y recursos, los cuales modifican y son modificados a su vez por las acciones de cada uno de los componentes.

La administración policial funciona a través de diversos procesos de trabajo específicos, que corresponden a funciones determinadas y necesarias para realizar el programa de trabajo y cumplir con el mandato policial: la planeación, el diseño organizacional, la dirección-control, y la evaluación.

Es estratégico y fundamental en la administración policial el subsistema de rendición de cuentas, ya que a través de éste la policía puede identificar y enfrentar la brecha existente entre los resultados del desempeño policíaco respecto a su mandato, además de cumplir con una condición de gobernabilidad, necesaria para un Estado moderno y democrático: la legitimidad del desempeño policial.

La administración policial y los procesos inherentes de rendición de cuentas posibilitan a las corporaciones de policía generar el conocimiento institucional que les permitan mejorar su desempeño y, por ende, reducir la brecha entre lo realizado y el mandato.

Los derechos humanos se establecen en el centro de la administración, el desempeño y la rendición de cuentas policial; por lo tanto, una definición de eficiencia policial debe considerar, explícitamente, el referente de los derechos humanos.

\section{BIBLIOHEMEROGRAFÍA}

ACERO, Hugo, La Seguridad Ciudadana es Responsabilidad de los Gobiernos Locales, en Ciudad y Seguridad en América Latina, FLACSO, Chile, 2005.

CANO, Ignacio, La policía y su evaluación. Propuestas para la construcción de indicadores de evaluación en el trabajo policial, Centro de Estudios para el Desarrollo, Chile, 2004.

CANDINA, Azun, Manual de Relaciones Policía Comunidad, Casos y Soluciones, Centro de Estudios de Seguridad Ciudadana, Chile, 2006.

Centro PRODH, INSYDE, Manual de Seguridad Ciudadana, Centro de Derechos Humanos Miguel Agustín Pro Juárez e Instituto para la Seguridad y la Democracia, México, 2009.

CERRILlo, Agustí (Coordinación), La Gobernanza Hoy: 10 Textos de Referencia, Instituto Nacional de Administración Pública, Madrid, 2005.

Citizen Focus, Local Policing Summaries. Good Practice Guide: Maximising Impact, Home Office, Reino Unido, 2007.

COHEN, Ernesto y Rolando Franco, Gestión social. Cómo lograr eficiencia e impacto en las políticas sociales, Siglo XXI/ CEPAL, México, 2005.

Comisión de las Comunidades Europeas, La gobernanza europea. Un libro blanco, Bruselas, 2001.

CRAWFORD, Adam, Prevención del delito y seguridad comunitaria, política, acción de gobierno y prácticas, Argentina, 1998. 
GARCÍA, Omar, Las políticas públicas: productos del sistema político, s/f, en http://www. ciudadpolitica.com/modules/news/article.php, consultado en septiembre de 2008.

GUNN, Lewis, Perspectives on Public Management, en Jan Kooiman y Kjell Eliassen (eds.), Managing Public Organizations, Sage, London, 1987.

HARMON, Michael, Teoría de la organización para la administración pública, Fondo de Cultura Económica, México, 1999.

LÓPEZ PORTILLO, Ernesto, Responsabilidad policial en democracia, una propuesta para américa latina, Instituto para la Seguridad y la Democracia, AC. y Centro de Estudios en Seguridad Ciudadana, México, 2008.

LYNN, Naomi y WILDAVSKY, Aaron, Administración pública. El Estado actual de la disciplina, Fondo de Cultura Económica, México, 1990.

MOCTEZUMA, Esteban y ROEMER, Andrés, Por un gobierno con resultados, Fondo de Cultura Económica, México, 2000.

PEAK, Kenneth y GAINES, Larry, Police Supervision and Management, In an Era of Community Policing, Pearson, Prentice Hall, USA, 2004.

ROBERG, Roy y KUYKENDALL, Jack, Police Management, Roxbury Publishing Company, San Jose State University, California, USA, 2002.

ROWLAND, Allison, La seguridad pública y el desarrollo humano en el ámbito local, PNUD, ONU, México, 2005.

SALAMANCA, Fernando, Análisis comparativo de sistemas de indicadores pertinentes a la relación entre policía y comunidad, CESC, Chile, 2004.

SIMON, H. A., Administrative Behavior, 3th edition, The Free Press, New York, 1976.

SÁNCHEZ, Fernando, Planificación estratégica y gestión pública por objetivos, en Serie Gestión Pública, núm. 32, Instituto Latinoamericano y del Caribe de Planificación Económica y Social-ILPES, CEPAL, Chile, 2003.

SCHEDLER, Andreas, ¿Qué es la rendición de cuentas?, en Cuadernos de Transparencia, núm. 3, IFAI, México, 2004.

SCHEIN, Edgar, La cultura empresarial y el liderazgo, Plaza y Janés, Barcelona, 1988.

TERRY, George, Principios de administración, CECSA, México, 2002.

VARENIK, Robert, Accountability. Sistema policial de rendición de cuentas, INSYDE/CIDE, México, 2005.

VILLALOBOS, Luis, Administración, reforma y rendición de cuentas policial en democracia, INAP-INSYDE, México, 2008.

WEBER, Max, La política como vocación, Alianza Editorial, trad. Francisco Rubio Llorente, México, 2009. 